\title{
Correlation of Occlusal-Plane-Inclination with Functional Condylar Displacement in Different Skeletal Classes
}

\author{
Markus Greven ${ }^{1,2, *}$, Igor Cazacu ${ }^{2,3}$, and Eva Piehslinger ${ }^{2}$ \\ ${ }^{1}$ Private Office, Bonn, Germany \\ ${ }^{2}$ University Dental School, Department of Prosthodontics, Medical University of Vienna, Austria \\ ${ }^{3}$ Private Office, Moldavia
}

*Corresponding author: Markus Greven, Private Office, Bonn, Germany, Tel: 49228 985900; E-mail: markusgreven@t-online.de

Received: 07 Feb, 2020 | Accepted: 28 Mar, 2020 | Published: 03 Apr, 2020

Citation: Greven M, Cazacu I, Piehslinger E (2020) Correlation of Occlusal-Plane-Inclination with Functional Condylar Displacement in Different Skeletal Classes. Int J Dent Oral Health 6(3): dx.doi.org/10.16966/2378-7090.321

Copyright: (C) 2020 Greven M, et al. This is an open-access article distributed under the terms of the Creative Commons Attribution License, which permits unrestricted use, distribution, and reproduction in any medium, provided the original author and source are credited.

\section{Abstract}

Objective: The aim of this study was to investigate the correlation between different skeletal classes, functional condylar displacement and the inclination of the upper posterior and upper anterior occlusal planes.

Methods: 150 patients out of a total of 700 were selected for the study based on recorded occlusal parameters, both genders from 18 years, using cephalostat, condylograph and Cadiax Diagnostic, Reference SL Articulator, Gamma dental software version 7.7.14.

Results: Condylar displacement was found in almost every second patient with different skeletal classes. The majority of patients show an aboveaverage steepness of occlusal plane (upper posterior occlusal plane more than the anterior one).

Conclusion: Over average steep Anterior Occlusal Plane (AOP) and Posterior Occlusal Plane (POP) is significantly correlated with retrusive mandibular/ condylar displacement in all skeletal classes, whereas in Skeletal class II the correlation is highly significant (Class II>I>III). We conclude that it is very important to determine the upper posterior and anterior occlusal planes for a detailed diagnosis to identify patients at risk of inducing functional complaints by dental treatment and to create an optimized treatment plan for each patient.

Keywords: Condylar displacement; Steepness of occlusal plane; Upper posterior occlusal plane; Upper anterior occlusal planes; Skeletal classes

\section{Introduction}

The skull/craniofacial system is the most complicated part in the human skeletal system with the main functions as connecting the brain [1] and participating in sensory and motor activities (smiling [2], talking and mastication [3]). The scope of this thesis pertains to the craniofacial system and the skeletal types that influence the motor functions of the craniofacial system.

Furthermore, dynamics of the craniofacial system [4] is related to the anatomy of the system [5] and the variety depends on the individual skeletal type.

Accordingly, the angular differences between upper and lower jaw influence the functioning of the craniofacial system [6,7]. This is also known as the proper or malocclusion of mandibular and maxillary system $[8,9]$.

Different planes influencing the occlusal function are [10]: Palatal Plane (PP), Occlusal Plane (OP) $[11,12]$ Mandibular Plane (MP), AB Plane (AB) [13].

Most important is the angle between the occlusal and the mandibular plane OP-MP [14]. Normally, the OP-MP angle is maintained constant $[15,16]$. However, during excessive displacement of the occlusal plane [17], a backward rotation of the mandible [18] takes place, which leads to an increase in the OP-MP angle [19]. Furthermore, during another instance of excessive displacement of the occlusal plane there is an insufficient vertical support of occlusion $[20,21]$ and hence the mandibular condyle stays restricted to grow [22,23] (Figures 1-4).

The Upper Anterior Occlusal Plane (UAOP) [24] is established by connecting the tip of upper central incisor with the cusp of the upper second premolar.

The Upper Posterior Occlusal Plane (UPOP) [24] is represented by the line that connects the cups of the upper second premolar with the occlusal surface of the upper second molar.

According to Angle's classification of malocclusions we differentiate between skeletal classes I (Neutroocclusion), II (Distocclusion, mandibular retrognathism/Overjet) and class III [25] (Mesiocclusion, mandibular prognathism/negative overjet).

Two subtypes of Dist occlusion are Class II, Division 1 with protruded upper anterior teeth and Class II, Division 2: here the 


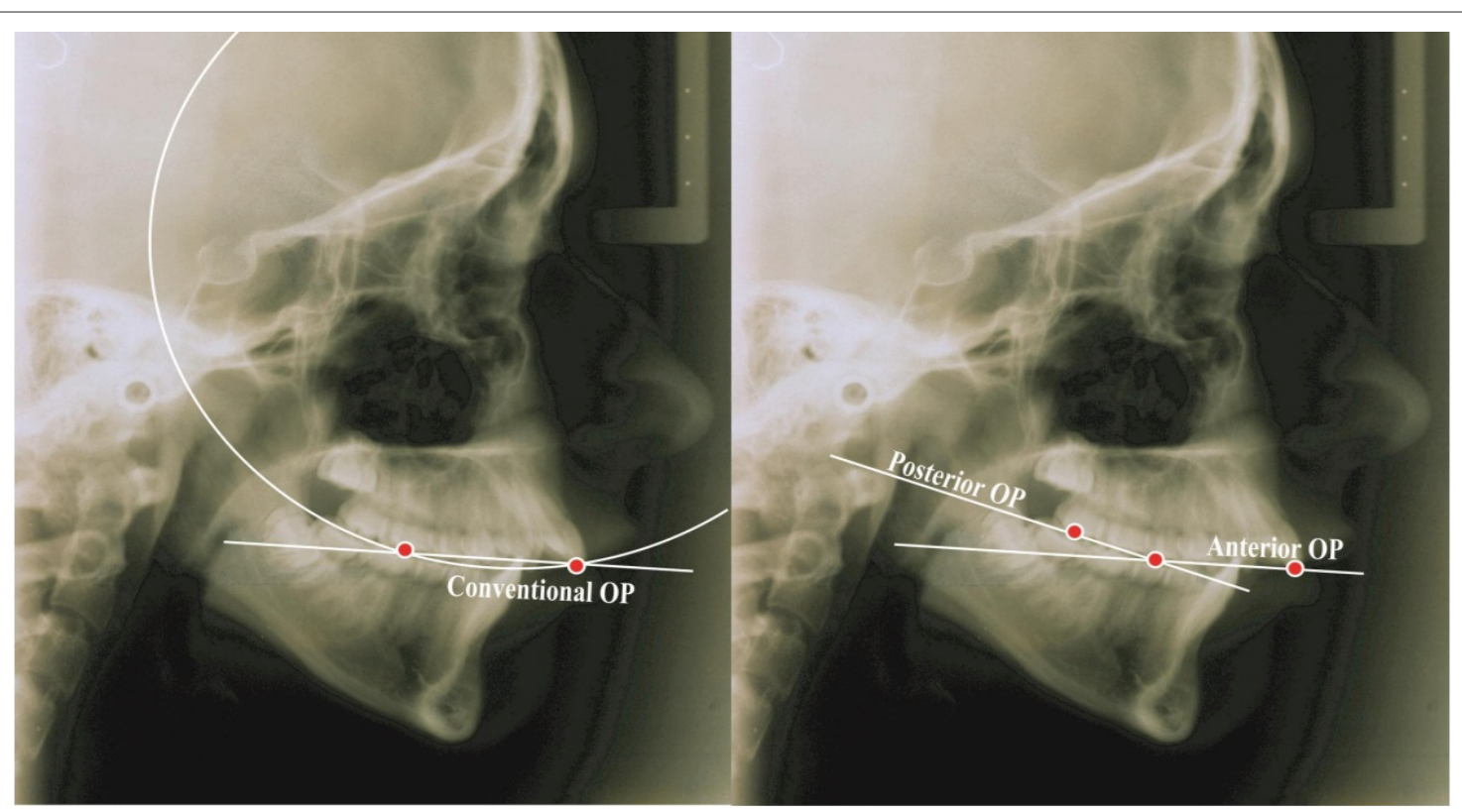

Figures 1 and 2: Difference between conventional occlusal plane and POP and AOP [24].
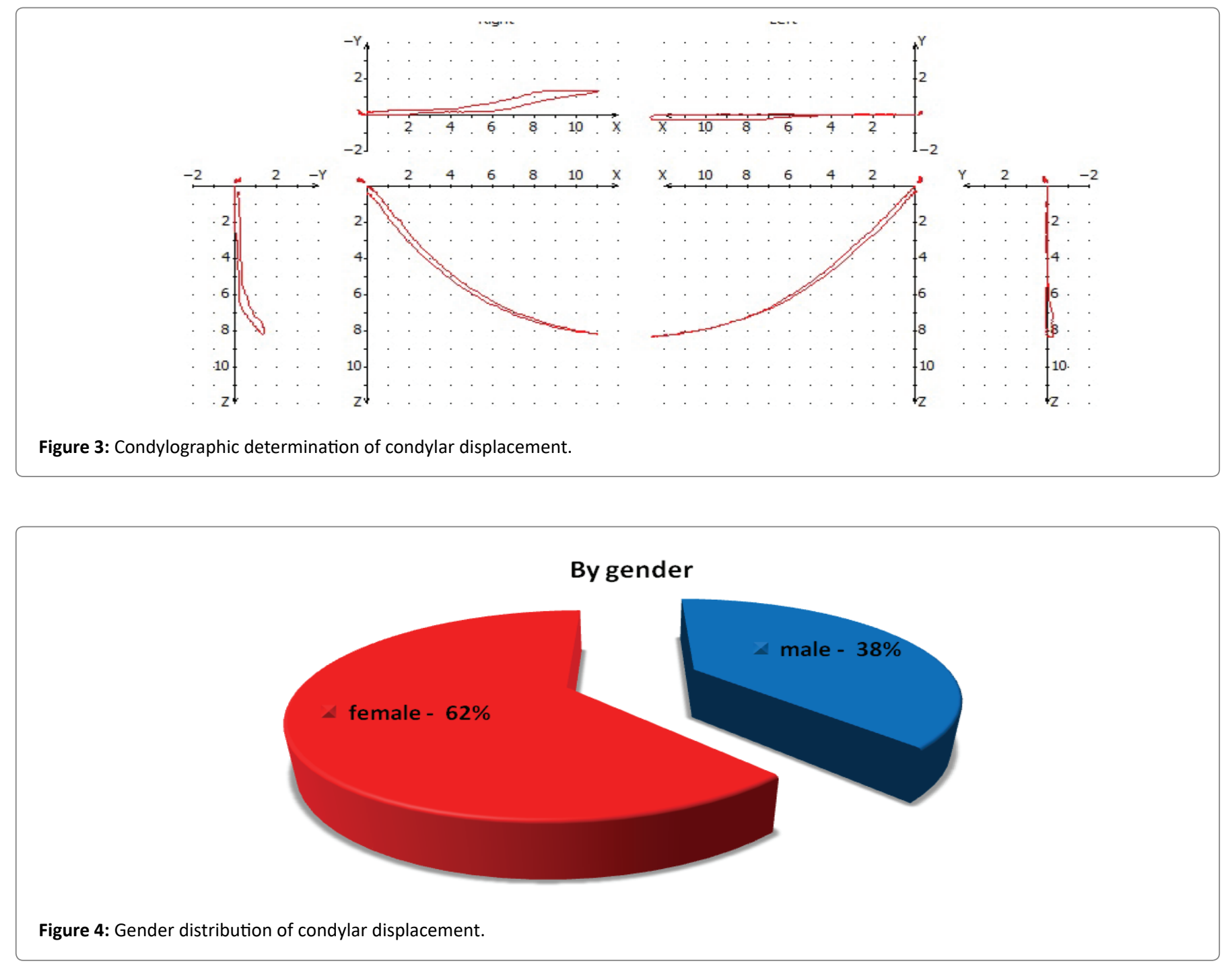
central incisors are retroclined while the lateral incisors overlap the central teeth.

Based on the concepts of occlusion by Professors Slavicek and Sato [26], we have taken up the case study of several patients in this thesis. Here we have analyzed a number of patients of different age groups and gender, healthy and with different dento-alveolar or functional anomalies.

For condylar position the orthodontists' purpose is a treatment result [27], where the upward and forward or a reference position $[28,29]$ of a condyle is constant with respect to the intercuspal position if the patient closes the mandible [30,31]. Is there a larger discrepancy between the seated condyle and tooth intercuspation pretreatment should be aimed for [32,33].

Moreover, the reference position, also known as the centric relation [34], provides a clear clinical indication whether the mastication process takes place properly or whether there is an excessive overbite or overjet.

Furthermore, to classify the patients, we have also determined the facial skeletal types of the subjects using the cephalometric analysis by Ricketts, Slavicek, Jarabak. In addition, facial skeletal types and resulting condylar displacements $[35,36]$ have a profound influence on the facial muscles [37] as well.

Our study's aim is to determine the correlation between different skeletal classes, condylar displacement $[38,39]$ and the inclination of the upper posterior and upper anterior occlusal planes [40-42].

Accordingly, the hypotheses for our study are:

- There is an evident correlation between an upper anterior and upper posterior occlusal plane with a condylar displacement in different skeletal classes.

- Condylar displacement is associated with a steeper posterior occlusal plane, especially in class II skeletal patterns.

\section{Materials and Methods}

A retrospective cephalometric and condylographic study was done with 150 patients out of a total of 700 patients. 500 of which were from Viesid database and 200 patients were the sample group for this study.

The selection criteria were:

- Recorded occlusal parameters of all patients

- Male and female from 18 years

- Patients with all teeth from inferior central incisor to second molar in all quadrants, with or without third molars

- Previously obtained informed consent to use patient data.

The technical equipment used was:

- Cephalostat

- Condylograph and Cadiax Diagnostic (Gamma Dental, Austria)

- Reference SL Articulator (Gamma Dental, Austria)

- Gamma Dental software version 7.7.14 (Gamma Dental, Austria).

The methods used for the research were as follows:

- Historical method

- Descriptive and analytical epidemiology

- Biostatistics

- Information transfer method
All patients took part in a standardized process:

- Questionnaire and special medical analysis (recent infections, problems with cardiovascular, respiratory, digestive or metabolic system, allergies, urogenital problems, problems related to the central nervous system, psychological problems, rheumatic disease, hormonal disorders or any special problems not listed here?)

- Dental history analysis

- Muscle and joint diagnosis (the state of muscles, both in the left and right sides of shoulders and neck, atlanto-occipital regions, anterior, medial and posterior temporal is muscles, superficial and deep masseter muscles, tuber maxillae muscles, pterygoideus medialis muscles, mylohyoideus muscles, digastricus muscles, supra and infra hyoidale muscles, laryngeal, sterno-cleidomastoeideus, omohyoideus and tongue muscles; for bone and joint assessments, the examinations involved comparative palpation of jaw joints, lateral poles statically, lateral points in rotation, retral joint space and temporomandibular ligament)

- Occlusogram-Brux checker

- Photographs of the patient (facial and oral)

- Study models (RP bite, face-bow)

- Condylography-Cadiax

- X ray-Panoramic [43], lateral and front cephalometric views $[44,45]$.

Classification of 150 patients into various skeletal classes, which were

- Class I-76 people (51\%),

- Class II-57 people (38\%),

- Class III-17 people (11\%).

A total of $49 \%$ of patients showed condylar displacement while the remaining $51 \%$ did not show any condylar displacement.

\section{Gender-wise distribution of condylar displacements (Figure 4)}

\section{Skeletal class-wise distribution of condylar displacements}

The majority of patients in the skeletal class II ( $n=36 / 63.15 \%)$ had condylar displacement. Amongst the patients classified in skeletal class I and skeletal class III there was an approximately equal percentage of patients with (w/d) and without (wo/d) condylar displacements (Class i: $w / d n=36 / 47,36 \%$; wo/d $n=40 / 52,63$ ) (Class III: w/d n=7/41, 2\%; wo/d $n=10 / 58,8 \%$ ) (Figure 5).

\section{Types of condylar displacements in all three skeletal classes}

Correlation between the upper anterior occlusal plane and condylar displacement in all of the three classes are represented in figures 6-8.

Correlation between the upper posterior occlusal plane and condylar displacement in all of the three classes are represented in figures 9-11.

The patient distribution for the condylar displacement related to the upper posterior occlusal plane and upper anterior occlusal planes respectively in all three skeletal classes were combined from the patients' collected data. The degrees of occlusal displacement in the upper anterior occlusal plane in all patients were from 67 to 92.9 and for the upper posterior occlusal plane in all patients from 59.9 to 93.6.

Combined graphical representations of all patients showing angular changes in either upper anterior occlusal plane or upper posterior occlusal plane are shown in figures 12 and 13. 


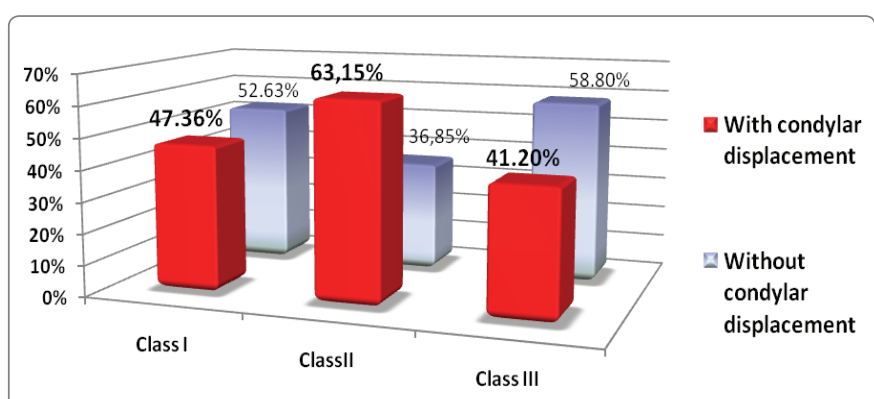

Figure 5: Condylar displacement by classes (relative values).

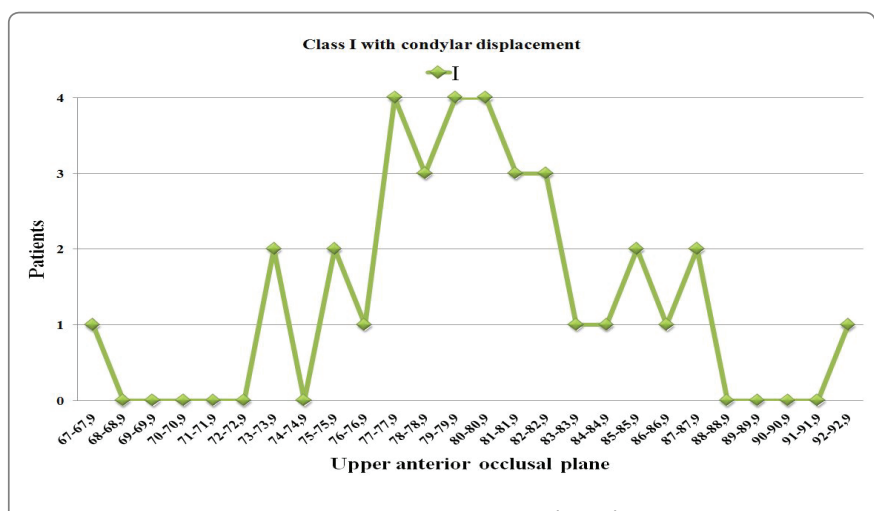

Figure 6: Class I with condylar displacement (AOP).

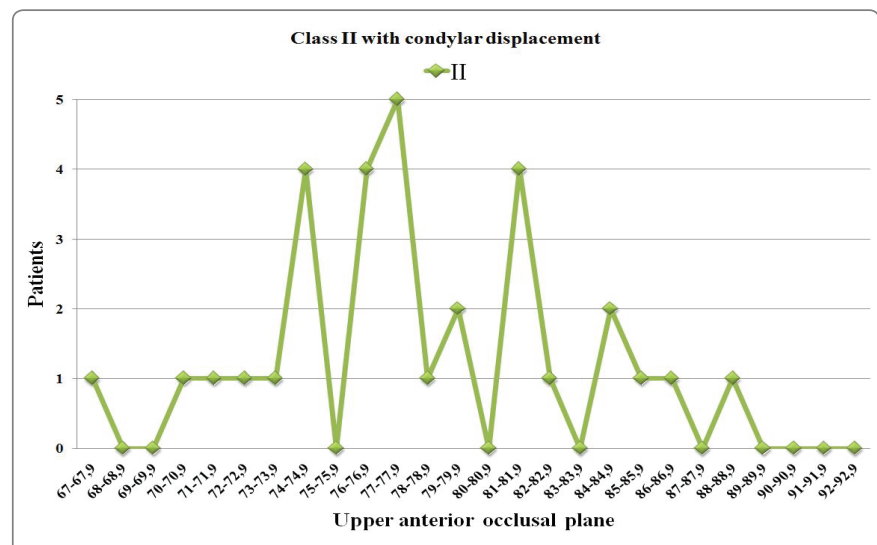

Figure 7: Class II with condylar displacement (AOP).

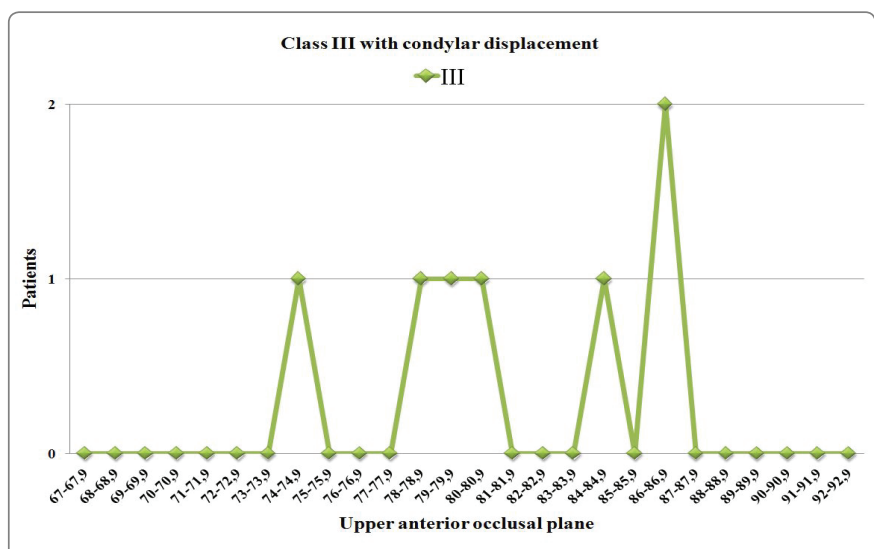

Figure 8: Class III with condylar displacement (AOP).

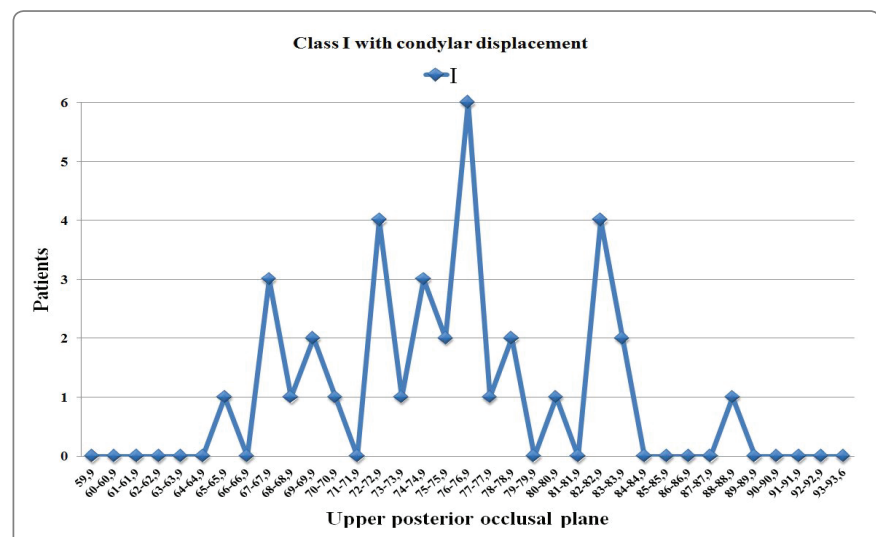

Figure 9: Class I with condylar displacement (POP).

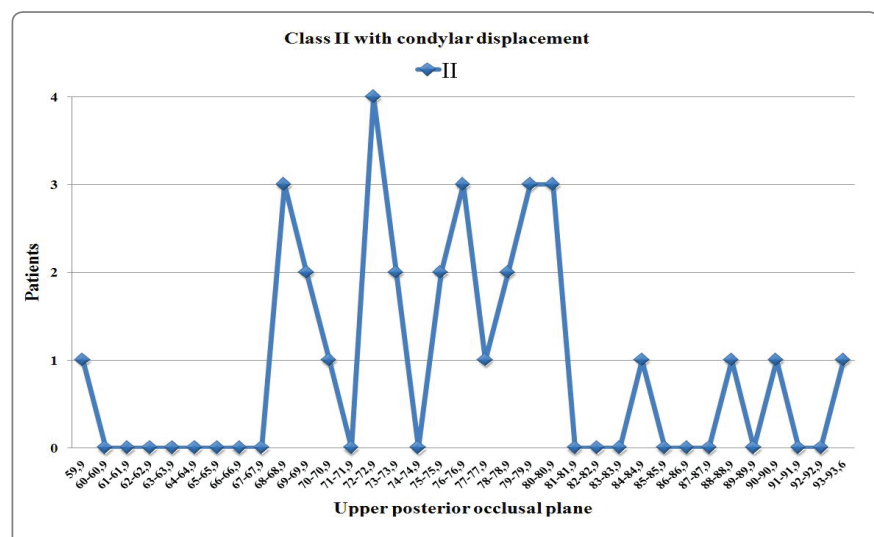

Figure 10: Class II with condylar displacement (POP).

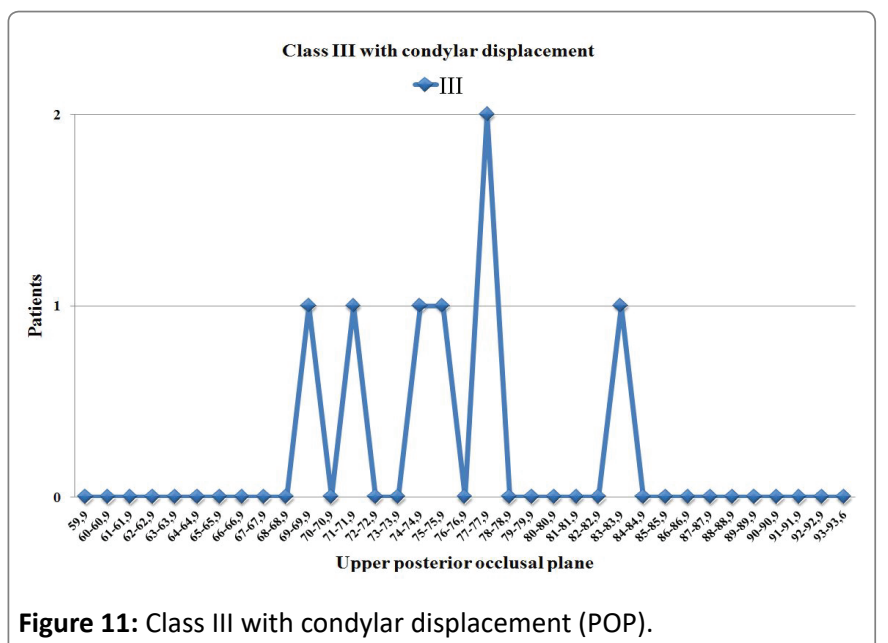

The $\mathrm{X}$ axis represents the angle of displacement and the $\mathrm{Y}$ axis represents the number of patients.

\section{Discussion}

An effective treatment of skeletal and dentoalveolar anomalies [46] including obtaining stable results [47] in time is primarily based on a detailed diagnosis [48] of all components of the stomatognathic system [49]. The condylar position is undoubtedly very important for a normal functionality of the temporomandibular joint [50] what 


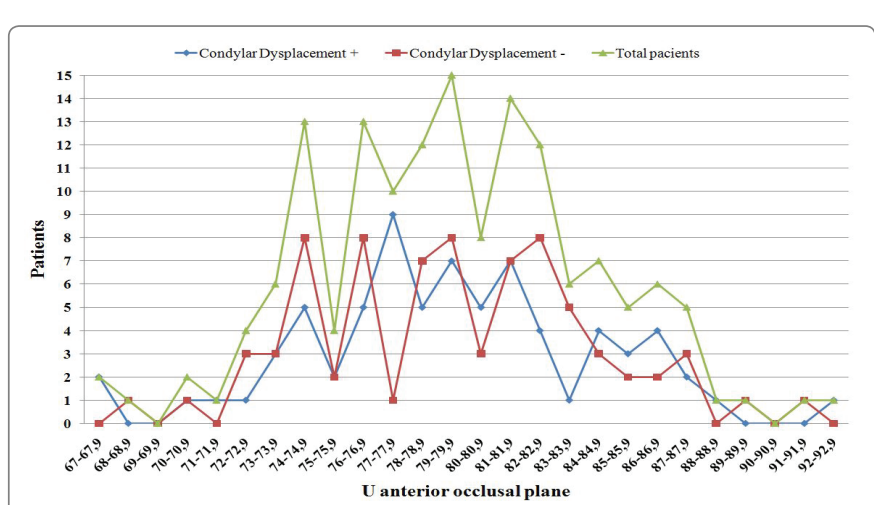

Figure 12: Patient distribution for the condylar displacement with regard to UAOP in all 3 skeletal classes.

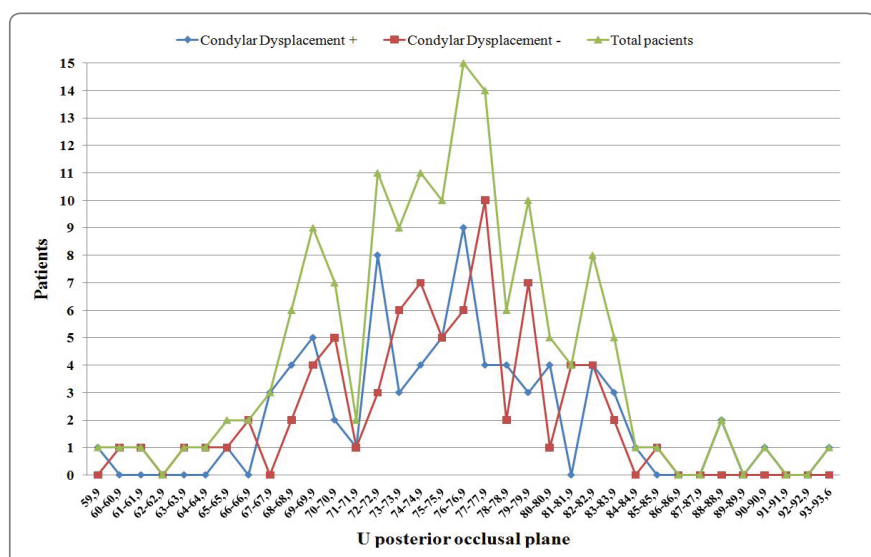

Figure 13: Patient distribution for the condylar displacement with regard to UPOP in all 3 skeletal classes.

has been demonstrated by the results of previous studies [51-53]. Compiling this data with the results of our study, we can conclude the following.

The majority of patients show an above-average steepness of the occlusal plane (upper posterior occlusal plane more than the anterior one).

A retruded condyle is an unfavorable "starting" position for the functions of the masticatory organ and is very often associated with functional disorders [29] (Weinberg LA, etc.).

A steep anterior occlusal plane [54] involves an avoidance pattern [55] due to the avoidance of too strong front tooth contacts in the transversal, retrusive or protrusive direction [56], leading to a load of the structures of the temporomandibular joint $[57,58]$ and to a constant hypertonicity of the muscles. This additional load involves a neurological reaction of the body leading to even more muscle activity $[26,1,39]$.

Moreover, in the majority of cases a steep posterior occlusal plane provides a significantly higher chance for the occurrence of laterotrusive and mediotrusive or even retrusive posterior interferences [59], again making an avoidance-which in turn will lead to more compensatory necessity of the system to increase the activity of the neurological system, enhanced muscle activity [60] and condylar displacement.

The analysis of data obtained from our study revealed that a majority of class II patients has condylar displacement. Also, almost every second investigated person with class I or III has condylar displacement.

Most patients with class I and condylar displacement have an upper posterior occlusal plane angle with values near 76-77 degrees. Most patients with class II and condylar displacement have the same angle with values between 67 and 81 degrees. Respectively, in class III this angle is about 77 degrees.

If we refer to the upper anterior occlusal plane angle, most patients with class I and condylar displacement reveal values between 76 and 81 degrees. Most patients with class II and condylar displacement have the same angle of 77 degrees. Respectively, in class III this angle is about 86 degrees.

So, if the majority of patients in all skeletal classes show this unfavorable starting position for dynamic function, it is absolutely necessary to pay special attention in dental treatment to the anterior and posterior occlusal plane [61] because there could be a high chance of overstraining the system in its adaptive capacities as they are already compensated in the majority of the cases [62].

According to Sato's concept [63] about the skeletal class II pattern with a steep posterior occlusal plane [9] and also reiterating the rapid historical increase of the class II incidence, we conclude that it is highly important to determine the upper posterior and anterior occlusal planes for a complex and detailed diagnosis.

Customized dentistry following the VieSID Sequential Occlusion with Canine Dominance concept should be based on an individual, thorough diagnosis using model analysis, cephalometric radiography, condylography, etc. It is highly recommended to use the upper anterior and posterior occlusal plane method to identify risk patients because of disclosed compensation and to choose the most reasonable treatment plan.

\section{Conclusion}

Over average steep Anterior Occlusal Plane (AOP) and Posterior Occlusal Plane (POP) is significantly correlated with retrusive mandibular/condylar displacement in all skeletal classes, whereas in Skeletal class II the correlation is highly significant (Class II $>$ I $>$ III). Steep Anterior and Posterior Occlusal Planes (AOP/POP) reduce the intercoronal functional freedom of functional mandibular movements and seems to induce muscular avoidance pattern with significant loading of the intra-articular structures of the temporo-mandibular joint and hereby bearing great risk of causing signs and symptoms of temporo-mandibular disorders such as muscle hypertonicity, muscle pain, internal derangement of the TMJ (capsulitis, synoviitis, tendinitis) and TMJ-pain.

We conclude that it is very important to determine the upper posterior and anterior occlusal planes for a detailed diagnosis to identify patients at risk of inducing functional complaints by dental treatment and to create an optimized treatment plan for each patient.

\section{Acknowledgment}

It is my great pleasure to say "thank you" to Professor Rudolf Slavicek and Sadao Sato for their historical wisdom, sharing of invaluable knowledge and friendly criticism.

Special thanks to my colleague, friend and a role model Valeriu Fala for his motivation and support.

I would also like to express appreciation to the most important teacher of my life who taught me not only to look but to see, to 
understand and to act right in my profession; you have been a tremendous mentor for me, to Dr. Yurie Baidauz.

\section{Declaration of Interest Statement}

The authors report no conflict of interest.

\section{References}

1. Otsuka T, Sasaguri K, Watanabe K, Hirano Y, Niwa M, et al. (2011) Influence of the TMJ position on limbic system activation-an fMRI study. J CranioMand Func 3: 29-39.

2. Batwa W, Hunt NP, Petrie A, Gill D (2012) Effect of occlusal plane on smile attractiveness. Angle Orthod 82: 218-223.

3. Bishara SE (2000) Facial and dental changes in adolescents and their clinical implications. Angle Orthod 70: 471-483.

4. Sato $S$ (2002) The dynamic functional anatomy of the cranio-facial complex and its relation to the articulations of the dentitions. In: Slavicek R (eds) The Masticatory Organ: Functions and Dysfunctions. GAMMA Medizinisch-wissenschaftliche Fortbildung-AG.

5. Manfredini D (2010) Current concepts on Temporomandibular Disorders. Quintessence.

6. Keller DC, Carano A (1991) Eminence-posterior occlusal plane angle in patients with temporomandibular disorders. Cranio 9: 159-164.

7. Kahn J, Tallents RH, Katzberg RW, Moss ME, Murphy WC (1998) Association between dental occlusal variables and intraarticular temporomandibular joint disorders: horizontal and vertical overlap. J Prosthet Dent 79: 658-662.

8. English JD, Buschang PH, Throckmorton GS (2002) Does malocclusion affect masticatory performance? Angle Orthod 72: 21-27.

9. Fushima K, Kitamura $Y$, Mita H, Sato S, Suzuki Y, et al. (1996) Significance of the cant of the posterior occlusal plane in class II division 1 malocclusions. Eur J Orthod 18: 27-40.

10. Jayachandran S, Ramachandran CR, Varghese R (2008) Occlusal plane orientation: a statistical and clinical analysis in different clinical situations. J Prosthodont 17: 572-575.

11. Kuno T, Hasegawa $M$, Okaue $M$, Matsunaga $S$, Matsumoto $M$, et al. (1994) Comparison of the functional occlusal plane in adults with class III malocclusion showing open bite and non-open bite. J Nihon Univ Sch Dent 36: 127-134.

12. Lin XF, Li SH, Huang ZS, Wu XY (2010) Relationship between occlusal plane and masticatory path in youth with individual normal occlusion. Zhonghua Kou Qiang Yi Xue Za Zhi 45: 370-375.

13. Kato T (1990) A study on the reference planes and lines for dental practice. Aichi Gakuin Daigaku Shigakkai Shi 28: 1-19.

14. Tanaka EM, Sato S (2008) Longitudinal alteration of the occlusal plane and development of different dentoskeletal frames during growth. Am J Orthod Dentofacial Orthop 134: 602e1-602e11.

15. Di Paolo RJ (1987) An individualized approach to locating the occlusal plane. Am J Orthod Dentofacial Orthop 92: 41-45.

16. Ogawa T, Koyano K, Suetsugu $T$ (1996) The relationship between inclination of the occlusal plane and jaw closing path. J Prosthet Dent 76: 576-580.

17. Bowley JF, Morgano SM (2001) Occlusal plane discrepancies generated by transverse horizontal axis deviations. J Prosthet Dent 86: 67-73.
18. Reyneke JP (1999) Surgical cephalometric prediction tracing for the alteration of the occlusal plane by means of rotation of the maxillomandibular complex. Int J Adult Orthodon Orthognath Surg 14: 55-64.

19. Del Santo M Jr (2006) Influence of occlusal plane inclination on ANB and Wits assessments of anteroposterior jaw relationships. Am J Orthod Dentofacial Orthop 129: 641-648.

20. Inoue T (1989) A study on mandibular displacement due to biting force. 2. Analysis of condylar displacement. Nihon Hotetsu Shika Gakkai Zasshi 33: 215-224.

21. Kurusu A, Horiuchi M, Soma K (2009) Relationship between occlusal force and mandibular condyle morphology. Evaluated by limited cone-beam computed tomography. Angle Orthod 79: 1063-1069.

22. Lötters FJ, Zwijnenburg AJ, Megens CC, Naeije M (1996) Relationship between condylar and incisor point displacement during habitual maximum open-close movements. J Oral Rehabil 23: 548-554.

23. Katsavrias EG (2002) Changes in articular eminence inclination during the craniofacial growth period. Angle Orthod 72: 258-264.

24. Slaviček M, Slavicek R (2002) The Masticatory Organ: Functions and Dysfunctions. In: Firma Fonograficzna (eds) $2^{\text {nd }}$ Edition, GAMMA 544.

25. Raymond JL, Matern O, Grollemund B, Bacon W (2010) Treatment of Class III malocclusion: the key role of the occlusal plane. Prog Orthod 11: 53-61.

26. Takero Otsuka DDS, Juri Saruta, M Greven, Y Ono, K Sasaguri, et al. (2011) Effects of orthodontic reconstruction on brain activity in a patient with masticatory dysfunction. Int J Stomatol Occlusion Med 4: 76-81.

27. Ruiken HM, Kuijpers-Jagtman AM (1992) Extraction of second molars as orthodontic therapy. Ned Tijdschr Tandheelkd 99: 169-171.

28. Girardot RA Jr (2001) Comparison of condylar position in hyperdivergent and hypodivergent facial skeletal types. Angle Orthod 71: 240-246.

29. Weinberg LA (1983) Definitive prosthodontic therapy for TMJ patients. Part I: Anterior and posterior condylar displacement. J Prosthet Dent 50: 544-557.

30. Bonilla-Aragon $\mathrm{H}$, Tallents RH, Katzberg RW, Kyrkanides S, Moss ME (1999) Condyle position as a predictor of temporomandibular joint internal derangement. J Prosthet Dent 82: 205-208.

31. Osborn JW (1987) Relationship between the mandibular condyle and the occlusal plane during hominid evolution: some of its effects on jaw mechanics. Am J Phys Anthropol 73: 193-207.

32. Lamarque $S$ (1995) The importance of occlusal plane control during orthodontic mechanotherapy. Am J Orthod Dentofacial Orthop 107: 548-558.

33. Ong HB, Woods MG (2001) An occlusal and cephalometric analysis of maxillary first and second premolar extraction effects. Angle Orthod 71: 90-102.

34. Hidaka O, Adachi S, Takada K (2002) The difference in condylar position between centric relation and centric occlusion in pretreatment Japanese orthodontic patients. Angle Orthod 72: 295301.

35. Kahl-Nieke B, Fischbach R (1999) Condylar restoration after early TMJ fractures and functional appliance therapy. Part II: Muscle evaluation. J Orofac Orthop 60: 24-38. 
36. Miyawaki S, Tanimoto $\mathrm{Y}$, Inoue $\mathrm{M}$, Sugawara $\mathrm{Y}$, Fujiki $\mathrm{T}$, et al. (2001) Condylar motion in patients with reduced anterior disc displacement. J Dent Res 80: 1430-1435.

37. Yang KH (1996) Modified Twin Blocks: fabrication method and use in a child with a Class II malocclusion. J Clin Pediatr Dent 20: 189-195.

38. Kersey ML, Nebbe B, Major PW (2003) Temporomandibular joint morphology changes with mandibular advancement surgery and rigid internal fixation: a systematic literature review. Angle Orthod 73: 79-85.

39. Park BK, Tokiwa O, Takezawa Y, Takahashi Y, Sasaguri K, et al. (2008) Relationship of tooth grinding pattern during sleep bruxism and temporomandibular joint status. Cranio 26: 8-15.

40. Ogawa T, Koyano K, Suetsugu T (1997) Characteristics of masticatory movement in relation to inclination of occlusal plane. J Oral Rehabil 24: $652-657$

41. Ogawa T, Koyano K, Suetsugu T (1998) Correlation between inclination of occlusal plane and masticatory movement. J Dent 26 : 105-112.

42. Ogawa T, Koyano K, Umemoto G (1998) Inclination of the occlusal plane and occlusal guidance as contributing factors in mastication. J Dent 26: 641-647.

43. Nedeljković N, Stamenković Z, Tatić Z, Racić A (2006) Possibilty of the lower third molar eruption--radiographic analysis. Vojnosanit Preg 63: 159-162.

44. Ferrario VF, Sforza C, Miani A Jr, Colombo A (1999) Simplified cephalometric lines for the estimation of muscular lines of action. Int J Adult Orthodon Orthognath Surg 14: 47-54.

45. Xie J, Zhao Y, Chao Y, Luo W (1993) A cephalometric study on determining the orientation of occlusal plane. Hua Xi Yi Ke Da Xue Xue Bao 24: 422-425.

46. Thayer TA (1990) Effects of functional versus bisected occlusal planes on the Wits appraisal. Am J Orthod Dentofacial Orthop 97: 422-426.

47. Rudolph DJ, Willes PMG, Sameshima GT (2001) A finite element model of apical force distribution from orthodontic tooth movement. Angle Orthod 71: 127-131.

48. Toll D, et al. (2010) MRI Findings in Patients with Skeletal Discrepancy. J Orofac Orthop 1.

49. Kobs G, Bernhardt O, Meyer G (2004) Accuracy of Computerized Axiography Controlled by MRI in Detecting Internal Derangements of the TMJ. Baltic Dent Maxillofac J 6: 7-10.
50. Sasaguri K, Ishizaki-Takeuchi R, Kuramae S, Tanaka EM, Sakurai T, et al. (2009) The temporomandibular joint in a rheumatoid arthritis patient after orthodontic treatment. Angle Orthod 79: 804-811.

51. Fujii T (2003) The relationship between the occlusal interference side and the symptomatic side in temporomandibular disorders. J Oral Rehabil 30: 295-300.

52. Fushima K, Akimoto S, Takamoto K, Sato S, Suzuki Y (1989) Morphological feature and incidence of TMJ disorders in mandibular lateral displacement cases. Nihon Kyosei Shika Gakkai Zasshi 48: 322-328.

53. Henrikson T, Ekberg EC, Nilner M (1997) Symptoms and signs of temporomandibular disorders in girls with normal occlusion and Class II malocclusion. Acta Odontol Scand 55: 229-235.

54. Santana-Penin UA, Mora MJ (1998) The occlusal plane indicator: new device for determining the inclination of the occlusal plane. J Prosthet Dent 80: 374-375.

55. Mongini F, Calderale PM, Barberi G (1979) Relationship between structure and the stress pattern in the human mandible. J Dent Res 58: 2334-2337.

56. Suzuki M (2006) The relationship between three-dimensional occlusal force and tooth displacement depending on clenching force in function. Kokubyo Gakkai Zasshi 73: 79-89.

57. Celić R, Jerolimov V, Pandurić J (2002) A study of the influence of occlusal factors and parafunctional habits on the prevalence of signs and symptoms of TMD. Int J Prosthodont 15: 43-48.

58. Clark GT (1991) Etiologic theory and the prevention of temporomandibular disorders. Adv Dent Res 5: 60-66.

59. Scrivani SJ, Keith DA, Kaban LB (2008) Temporomandibular disorders. N Engl J Med 359: 2693-2705.

60. Sheikholeslam A, Holmgren K, Riise C (1993) Therapeutic effects of the plane occlusal splint on signs and symptoms of craniomandibular disorders in patients with nocturnal bruxism. J Oral Rehabil 20: 473482.

61. Simoes WA (1995) Occlusal plane: a clinical evaluation. J Clin Pediatr Dent 19: 75-81.

62. Stipetić J, Celebić A, Baucić I, Lazić B, Komar D, et al. (2001) Analysis of occlusal contacts in different types of prosthodontic appliances, Eichner classifications, presence RCP-ICP slide and the type of occlusion. Coll Antropol 25: 311-316.

63. Sato M, Motoyoshi M, Hirabayashi M, Hosoi K, Mitsui N, et al. (2007) Inclination of the occlusal plane is associated with the direction of the masticatory movement path. Eur J Orthod 29: 21-25. 